\title{
A study to investigate the effectiveness of successful intelligence training program to increase academic hope
}

\author{
Mahbobeh Samavatian $^{\mathrm{a}^{*}}$, Zohreh Latifi ${ }^{\mathrm{b}}$ and Ahmad Abedi
}

${ }^{a}$ Department of Humanities Science College of Counseling, Yazd Science Research Branch, Islamic Azad University, Yazd, Iran

${ }^{b}$ Assistant Prof., Payame Nour University, Esfahan, Iran

${ }^{c}$ Assistant Prof., Department of Psychology, University of Esfahan, Esfahan, Iran

\section{H R O N I C L E}

\section{Article history:}

Received June 28, 2013

Received in revised format

19 October 2013

Accepted 23 October 2013

Available online

December 122013

Keywords:

Successful Intelligence

Intelligence Analytical

Creative intelligence

Practical Intelligence

Hope

Probation students

\section{A B S T R A C T}

The purpose of this study is to investigate the effectiveness of successful intelligence training program on academic hopefulness of probation students of Esfahan University of Technology. The research is semi-experimental of pre-test, post-test type with control group. Research population includes all probation students of Esfahan University of Technology. The study chooses 30 female and male students and assigns them randomly into two groups of experimental and control. Experimental group participate in 13 successful intelligence-training sessions for 13 weeks. Research tools consists of, Hope in certain aspects. Statistical analysis is conducted using SPSS18 on inferential statistics level proportionate to data analysis level. Statistical test hypothesis are analyzed through univariate covariance and multivariate covariance analysis. The results show that successful intelligence program training was effective to enhance hopefulness of probation students $(p<0.05)$. Given the results of present research, successful intelligence program training can be used as an intervention method in order to decrease harms because of dormitory and student life.

\section{Introduction}

During the past few years, there have been various studies on the effectiveness of successful intelligence program training on academic hopefulness of various societies (Sternberg \& Grigorenko, 1997; Sternberg, 1985; Healy, 2005; Fredrickson, 2009). Chimich and Nekolaichuk (2004), for instance, explored the links between depression, integrity, and hope in the elderly. They suggested that depression, integrity, and hope were highly interrelated in the elderly population and it could affect mastery of the developmental tasks of aging. Motlagh et al. (2008) investigated the factors influencing students' academic failure in Jondishapour University of Medical Sciences over the period 2004-2005. They reported that the effective variables on academic performance and students' educational failure, the educational authorities could make appropriate plans and strategies to identify at risk students and provide proper consultation and better facilities for them.

*Corresponding author. Tel: +989131250942

E-mail addresses: m1_sama@yahoo.com (M. Samavatian) 
Shure and Spivack (1981) examined an experimental model on the mediating function of interpersonal cognitive problem solving skills on behavioral adjustment in preschool and kindergarten children. They identified two significant behavioral mediators in young children; a beginning had been made to isolate specific thinking skills, which, if enhanced, could contribute to healthy social adjustment and interpersonal competence at an early age. Sternberg (2004) explained that intelligence cannot be recognized outside its cultural context and they considered the relevance of culture to intelligence, as well as its investigation, assessment, and development. They described the importance of understanding intelligence in its cultural context and concluded that intelligence must be understood in such context.

Schunk (1996) performed two studies on how goals and self-evaluation influence motivation and achievement outcomes. In both works, fourth-grade students received instruction and practice on fractions over sessions. Students worked under conditions involving either an objective of learning how to solve problems or an objective of merely solving them. In the first study, half of the students in each goal condition assessed their problem-solving capabilities. The learning objective with or without self-evaluation and the performance objective with self-evaluation led to higher self-efficacy, skill, motivation, and task orientation than did the performance objective without self-evaluation. In the second study, all students in each objective condition assessed their progress in skill acquisition. The learning objective led to higher motivation and achievement outcomes than did the performance objective.

Snyder et al. (2002) introduced a cognitive, motivational theory to the educational research community. In this study, hope theory integrated the conceptualization of goals, along with the strategies to reach those objectives, and the motivation to pursue those objectives. In a six-year longitudinal investigation, individual differences in hope, as computed by the Hope Scale (Snyder et al., 1991; 1994) scores of entering college freshmen, predicted better overall grade point averages even after controlling for variance associated with entrance examination scores. High- relative to the low-hope students also were more likely to have finished their programs and not to have been dismissed over this six-year time schedule.

\section{The proposed study}

The purpose of this study is to investigate the effectiveness of successful intelligence program training on academic hopefulness of probation students of Esfahan University of Technology. The research is semi-experimental of pre-test, post-test type with control group. Research population includes all probation students of Esfahan University of Technology. The study chooses 30 female and male students and assigns them randomly into two groups of experimental and control. Experimental group participate in 13 successful intelligence training-program sessions for 13 weeks. Research tools consists of, Hope in certain aspects (Simpson \& Snyder, 1999). Statistical analysis is conducted using SPSS18 on inferential statistics level proportionate to data analysis level. Statistical test hypothesis are analyzed through univariate covariance and multivariate covariance analysis. Table 1 demonstrates the result of Kolmogorov-Smirnov test to examine whether the data are normally distributed. As we can observe from the results of Table 1, all data are normally distributed when the level of significance is five percent.

Table 1

The summary of the results of Kolmogorov-Smirnov for pre-test and pos-test

\begin{tabular}{|c|c|c|c|c|c|c|c|c|c|c|c|c|c|}
\hline & & \multicolumn{6}{|c|}{ Pre-test } & \multicolumn{6}{|c|}{ Post-test } \\
\hline & & $\mathrm{R}$ & E & $\mathrm{L}$ & $\mathrm{F}$ & $\mathrm{J}$ & Total & $\mathrm{R}$ & E & $\mathrm{L}$ & $\mathrm{F}$ & $\mathrm{J}$ & Total \\
\hline \multirow{2}{*}{ Experiment } & Z & 0.515 & 0.422 & 0.473 & 0.613 & 0.645 & 0.56 & 0.686 & 0.656 & 0.541 & 0.891 & 0.357 & 0.579 \\
\hline & Sig. & 0.935 & 0.994 & 0.979 & 0.846 & 0.799 & 0.912 & 0.735 & 0.783 & 0.931 & 0.406 & 1 & 0.89 \\
\hline \multirow{2}{*}{ Witness } & $\mathrm{Z}$ & 0.639 & 0.547 & 0.402 & 0.593 & 0.701 & 0.149 & 0.555 & 0.812 & 0.723 & 0.612 & 0.629 & 0.434 \\
\hline & Sig. & 0.809 & 0.926 & 0.997 & 0.873 & 0.71 & 0.142 & 0.917 & 0.525 & 0.672 & 0.848 & 0.824 & 0.992 \\
\hline
\end{tabular}


In addition, Table 2 demonstrates the results of some basic statistics associated with pre-test and posttest. As we can observe from the results of Table 2, the mean of scores has been slightly changed from pre-test to post-test. Now, we perform Levin test to find out whether the variances of data are equal or not. Our survey indicates that F-value is equal to 4.1 with Sig. $=0.052$, which means the preassumption of having equal variances holds. Therefore, we can perform ANOVA test and the results are summarized in Table 3.

Table 2

The summary of some basic statistics

\begin{tabular}{ccccc}
\hline Statistics & Pre-test in & Pre-test in & Post-test in & Post-test in \\
\hline Mean & 3.04 & 3.08 & 2.66 & 3.38 \\
Standard & 0.51 & 0.49 & 0.54 & 0.39 \\
\hline
\end{tabular}

Table 3

The summary of ANOVA test

\begin{tabular}{cccccccc}
\hline Group & $\begin{array}{c}\text { Sum of } \\
\text { squares }\end{array}$ & df & $\begin{array}{c}\text { Mean of } \\
\text { squares }\end{array}$ & F & Sig. & Effective & $\begin{array}{c}\text { Power of } \\
\text { statistics }\end{array}$ \\
\hline Group membership & 3.64 & 1 & 3.64 & 26.77 & 0.000 & 0.49 & 0.999 \\
Pre-test score & 2.65 & 1 & 3.65 & 19.48 & 0.000 & 0.42 & 0.989 \\
\hline $\mathrm{R}^{2}=0.64$ Adjusted $\mathrm{R}^{2}=0.61$ & & & & & & &
\end{tabular}

The results of Table 3 clearly indicate that the results are statistically significant and we can conclude that the successful intelligence program has been effective. Now, we perform the test for various components of hope survey and the results are given in Table 4 as follows.

Table 4

The results

\begin{tabular}{|c|c|c|c|c|c|c|c|c|}
\hline Source & Statistics & Value & $\mathrm{F}$ & df & $\begin{array}{l}\text { df of } \\
\text { error }\end{array}$ & Sig. & Effect & $\begin{array}{l}\text { Power of } \\
\text { statistics }\end{array}$ \\
\hline \multirow{4}{*}{$\begin{array}{c}\text { Group } \\
\text { membership }\end{array}$} & Pilla effect & 0.634 & 6.226 & 5 & 18 & 0.002 & 0.634 & 0.975 \\
\hline & Wilkes & 0.366 & 6.226 & 5 & 18 & 0.002 & 0.634 & 0.975 \\
\hline & Hoteling & 1.729 & 6.226 & 5 & 18 & 0.002 & 0.634 & 0.975 \\
\hline & Highest root & 1.729 & 6.226 & 5 & 18 & 0.002 & 0.634 & 0.975 \\
\hline \multirow{4}{*}{$\begin{array}{l}\text { Hope in social } \\
\text { relationship }\end{array}$} & Pilla effect & 0.74 & 10.242 & 5 & 18 & 0 & 0.74 & 0 \\
\hline & Wilkes & 0.26 & 10.242 & 5 & 18 & 0 & 0.74 & 0 \\
\hline & Hoteling & 2.845 & 10.242 & 5 & 18 & 0 & 0.74 & 0 \\
\hline & Highest root & 2.845 & 10.242 & 5 & 18 & 0 & 0.74 & 0 \\
\hline \multirow{4}{*}{$\begin{array}{l}\text { Hope in } \\
\text { education }\end{array}$} & Pilla effect & 0.572 & 4.803 & 5 & 18 & 0.006 & 0.572 & 0.923 \\
\hline & Wilkes & 0.428 & 4.803 & 5 & 18 & 0.006 & 0.572 & 0.923 \\
\hline & Hoteling & 1.334 & 4.803 & 5 & 18 & 0.006 & 0.572 & 0.923 \\
\hline & Highest root & 1.334 & 4.803 & 5 & 18 & 0.006 & 0.572 & 0.923 \\
\hline \multirow{4}{*}{ Hope in leisure } & Pilla effect & 0.795 & 13.976 & 5 & 18 & 0 & 0.795 & 1 \\
\hline & Wilkes & 0.205 & 13.976 & 5 & 18 & 0 & 0.795 & 1 \\
\hline & Hoteling & 3.882 & 13.976 & 5 & 18 & 0 & 0.795 & 1 \\
\hline & Highest root & 3.882 & 13.976 & 5 & 18 & 0 & 0.795 & 1 \\
\hline \multirow{4}{*}{$\begin{array}{l}\text { Hopes in family } \\
\text { relationship }\end{array}$} & Pilla effect & 0.732 & 9.817 & 5 & 18 & 0 & 0.732 & 0.999 \\
\hline & Wilkes & 0.268 & 9.817 & 5 & 18 & 0 & 0.732 & 0.999 \\
\hline & Hoteling & 2.727 & 9.817 & 5 & 18 & 0 & 0.732 & 0.999 \\
\hline & Highest root & 2.727 & 9.817 & 5 & 18 & 0 & 0.732 & 0.999 \\
\hline \multirow{4}{*}{$\begin{array}{c}\text { Hopes in carrier } \\
\text { path }\end{array}$} & Pilla effect & 0.64 & 6.4 & 5 & 18 & 0.001 & 0.64 & 0.978 \\
\hline & Wilkes & 0.36 & 6.4 & 5 & 18 & 0.001 & 0.64 & 0.978 \\
\hline & Hoteling & 1.778 & 6.4 & 5 & 18 & 0.001 & 0.64 & 0.978 \\
\hline & Highest root & 1.778 & 6.4 & 5 & 18 & 0.001 & 0.64 & 0.978 \\
\hline
\end{tabular}

According to the results of Table 4, we can conclude that all components of the survey are statistically meaningful when the level of significant is five percent. In other words, when the scores of pre-test are removed the effects of successful intelligence program in social relationship, hope in 
education, hope in leisure, hope in family relationship and hope in carrier path are $0.634,0.74,0.572$, $0.795,0.732$ and 0.64 , respectively. These results confirm that the test has effectively influenced on our participants, positively.

\section{Conclusion}

In this paper, we have presented an empirical investigation to study the effect of successful intelligence program on increasing university students' hope. The proposed study has implemented a standard test to examine the effect of training program in terms of five perspectives including hope in social relationship, hope in education, hope in leisure, hope in family relationship and hope in carrier path and the results have been able to improve the hope among these students. The results of this survey are consistent with findings reported by Bilchik (1999) to increase hope in family relationship. The results are also consistent with Sternberg (2004) in terms of hope in education.

\section{Acknowledgement}

The authors would like to thank the anonymous referees for constructive comments on earlier version of this paper.

\section{References}

Bilchik, S. (1999). Minorities in the juvenile justice system. US Department of Justice.

Chimich, W. T., \& Nekolaichuk, C. L. (2004). Exploring the links between depression, integrity, and hope in the elderly. Canadian journal of psychiatry. Revue canadienne de psychiatrie, 49(7), 428433.

Fredrickson, B. (2009). Positivity: Groundbreaking Research Reveals How To Embrace The Hidden Strength Of Positive Emotions, Overcome Negativity. New York: Grown Publishing.

Healy, A. F. (2005). Experimental cognitive psychology and its applications. American Psychological Association.

Motlagh, M. E., Elhampour, H., \& Shakurnia, A. (2008). Factors affecting students' academic failure in Ahvaz Jundishapur University of Medical Sciences in 2005. Iranian Journal of Medical Education, 8(1), 91-99.

Schunk, D. H. (1996). Goal and self-evaluative influences during children's cognitive skill learning. American Educational Research Journal, 33(2), 359-382.

Shure, M. B., \& Spivack, G. (1981). Interpersonal problem solving as a mediator of behavioral adjustment in preschool and kindergarten children. Journal of Applied Developmental Psychology, 1(1), 29-44.

Sternberg, R. J., \& Grigorenko, E. L. (Eds.). (1997). Intelligence, heredity and environment. New York: Cambridge University Press.

Sternberg, R.J. (1985). Beyond IQ: A triarchic theory of human intelligence. New York: Cambridge University Press.

Sternberg, R. J. (2004). Culture and intelligence. American psychologist, 59(5), 325-338.

Snyder, C. R. (1991). Reality Negotiation and Excuse-making. In Handbook of social and clinical psychology: The health perspective, ed. C.R. Snyder and D.R. Forsyth . Elmsford, N.Y.:Pergamon.

Snyder, C. R. (1994). The Psychology of Hope: You Can Get there from here. New York: Free Press.

Snyder, C. R., Shorey, H. S., Cheavens, J., Pulvers, K. M., Adams III, V. H., \& Wiklund, C. (2002). Hope and academic success in college. Journal of educational psychology, 94(4), 820. 